\title{
Prediction the data consumption for power demands by Elman neural network
}

\author{
Lafta Ismael $^{1}$, Ammar Issa Ismael ${ }^{2}$ \\ ${ }^{1}$ Department of Electronics Engineering, College of Engineering, Dyala University, Iraq \\ ${ }^{2}$ Department of Electrical power and Machine Engineering, College of Engineering, Dyala University, Iraq
}

\begin{abstract}
Article Info
Article history:

Received Oct 3, 2018

Revised Feb 24, 2019

Accepted May 1, 2019

\section{Keywords:}

Identification by neural network Modeling

ABSTRACT

The load forecasting consider as part important in power system operation. The exact prediction for power demand is important for planning how much need extra power generation to cover extra load to keep without happen shutdown. Neural networks stay frequently designed for modeling dynamic processes. The Multi-Layer Perceptron (MLP) with Radial Basis Functions (RBF) network is static approximations used fewer frequently in the discretetime domain. In this paper proposed predict method for daily peak load by Elman Neural Network (ENN) with using data power demand for 2 years collected from National Control Center (NCC) and comparing the result. The result show the proposal is evaluated and followed the power demand.
\end{abstract}

Power demands

Power systems

Copyright $(0) 2019$ Institute of Advanced Engineering and Science. All rights reserved.

\section{Corresponding Author:}

Ammar Issa Ismael,

Department of Electrical power and Machine Engineering,

Dyala University,

Qudas Square, Baquba, Dyala, Iraq.

Email: ammarissa1978@gmail.com

\section{INTRODUCTION}

A key instrument in power system operation is the load forecasting. Several operating decisions are depend on load forecasts, for example reliability analysis, dispatch scheduling, and maintenance plan used for the generators. In spesific, load forecasting is more significant due to the increase of deregulation and free rivalry of the electric power industry totally everywhere in the world. Load forecasts are vital used for the energy dealings in competitive electricity markets. Furthermore, the accurate predictable for the load is important data for electricity price forecast [1]. In [2] paper presented a schem of computational intelligence founded the SVR and SOM is useful to rebuild the electricity load forecasting dynamics by using a time series approach.

In Iraq, the power generation isn't sufficient the power demand because the wars, administrative corruption and as well as collapse of the transmission lines [3]. So the shut down in the power system is happen for several times, to avoid this problem the ministry of electrical in Iraq but table for shut down partly especially in winter and summer seasons. In this case the estimated loads forecast is difficult with absence the whole data.

The modeling dynamic process by neural networks are often used forsyastems [4, 5]. In most cases, one hidden layer is used with Multi-Layer Perceptron network, the Radial Basis Functions (RBF) network is used much less frequently. Both RBF and MLP neural netwroks structures are static estimations. By delivering the values of the signal of input and output from some previous sampling instants to the input nodes of the network (by the delay lines) to the dynamics is introduced into the static networks when they are used for dynamic modeling processes (in the discrete-time domain). 
A recurrent neural networks used for approximation of static neural with lines of delay is to use $[5,6]$, that are models of synamic dynamic by nature. Elman neural network is an example of recurrent neural networks [7, 8]. In Elman neural network [7] there is no addition time-delay, while many process of technologic dynamic, in specific in petrochemical, food industries and ,chemical, are distinguished by comparatively long unmixed time-delay, that may product from the time necessary to achieve the measurements. Intuitively, the Elman neural network may be not the greatest solution. In this paper; we present our algorithm on the task of Elman Neural Network (ENN) to estimatet the peak of load everyday for the next day in whole month. To assess the production of the technique of forecasting power load data acquired as of National Control Center (NCC) for Mininistry of Iraq Electrical power.

\section{RESEARCH METHOD}

For clarify and simplicity of giving the dynamic systems of single-input single-output that are examined in this paper. The input signal is designated by $\mathrm{u}$, the signal of output is designated by $\mathrm{y}$. The presented sampling instant is designated by $\mathrm{k}$. The Elman recurrent neural network in Figure 1 displays the form of the Elman neural network method. The network has one input connected with the input signal of the operation from the preceding sampling instant, i.e. $\mathrm{u}(\mathrm{N}-1), \mathrm{N}$ the hidden neurons layer with a transfer function in nonlinear $\varphi: R \rightarrow R$, one neuron and with one output $y(k)$. The signals of output for the hidden layer $\left(\mathrm{v}_{-} 1(\mathrm{~N}), \ldots \ldots, \mathrm{v} \mathrm{N}_{-} \mathrm{N}(\mathrm{N})\right)$ are accessed through single delay bocks to the nodes of input signal for the networ that means that the network has $\mathrm{N}+1$ the nodes of input $\mathrm{u}(\mathrm{N}-1), \mathrm{v} \_1(\mathrm{~N}-1), \ldots, \mathrm{v} \_\mathrm{N}(\mathrm{N}-1)$. The second layer weights of the network are designated by $\mathrm{w}_{-} \mathrm{i}^{\wedge}((2))$ for $\mathrm{i}=0, \ldots ., \mathrm{N}$, the first layer weights of the network $\mathrm{w}_{-}(\mathrm{i}, \mathrm{j})^{\wedge}((1))$ for $\mathrm{i}=1, \ldots, \mathrm{N}, \mathrm{j}=0, \ldots, \mathrm{N}+1$. Both layers have an additional unity signal (bias signal). SVR is useful to use a time series approach in reconstruct the electricity load forecasting dynamics.

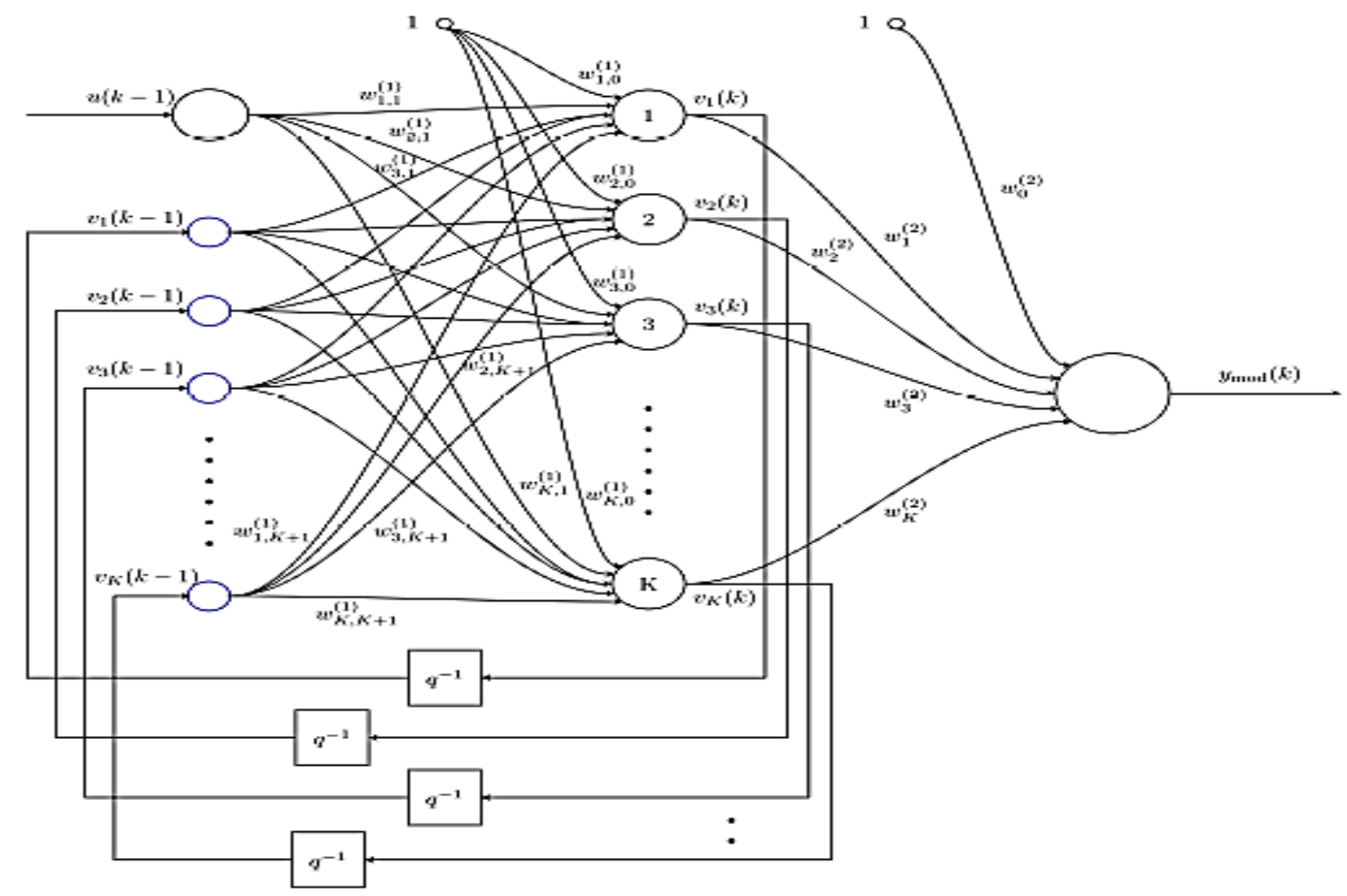

Figure 1. Elman neural network structure

In Iraq, the power generation isn't sufficient the power demand because the wars, administrative corruption and as well as collapse of the transmission lines [3]. So the shut down in the power system is happen for several times, to avoid this problem the ministry of electrical in Iraq but table for shut down partly especially in winter and summer seasons. In this case the estimated loads forecast is difficult with absence the whole data. 
Modeling dynamic processes did by using neural networks [4, 5]. The Multi-Layer Perceptron (MLP) network is used with one hidden layer, the network with Radial Basis Functions (RBF) is used much less frequently. The neural structures of Both RBF and MLP are in fact static approximations. The dynamics is applied into the static networks by sending the values of the input and output signals from some preceiding sampling instants to the input nodes of the network when they are used for dynamic modeling processes.

An absorbing alternative to approximations of static neural with delay lines is to use recurrent neural networks [5,6] that are dynamic models by nature. One well-known case of recurrent neural networks is Elman neural network [7, 8]. In the recurrent Elman neural network [7] there is no additional time-delay, while many of processes of technological dynamic, in particular in chemical, food and petrochemical.

Kosay A. S. Majbor, Qais M. Alias, and Kadhim M. Sulaiman proposed to solve the problem of uncertainty of the load forecast that is partly due to the sudden rise in the consumer buying power with the electricity generation deficit. They worked on load forecasting for Ireaq power network for whole of years with the averging method and the minimum - maximum. Their results obtained close to the adopted load forecasts for years with high value in error but they didn't get estimation for future years [9].

Dr. Adel M. Dakhil proposed to develop electric load forcasting with short term by neural network depended on historical series of power demand the neural network chosen if feed foeward network in (daily hour, the weekly day and load of the previous hour), this method was good accuracy and robust in forecasting but it not included for future estimation [10].

The peper show the solution the problems of power demand forecast for (hour of days and days of week and weekd of months and estimation for future year), the work with Elman neural network was very close to ther real with minimum error. The Elman neural network is very good method to estimate the real value and with validation we can estimate the future at any time or any day of next years.

\section{ELMAN NEURAL NETWORK ALGORITHM}

One has

Where $v_{i}(N)(\mathrm{N})$ stands for the output signals of consecutive hidden nodes $(=1, \ldots, N), v_{o}(N)=1$.

$$
v_{i}(N)=\varphi\left(z_{i}(N)\right)
$$

where the signals sum of the $i^{\text {th }}$ hidden node is

$$
z_{i}(N)=w_{i, 0}^{(1)}+w_{i, 1}^{(1)} u(N-\tau)+\sum_{j=1}^{N} w_{i, i+1}^{(1)} v_{j}(N-1)
$$

Combining all equations above, we get

$$
y(k)=w_{0}^{(2)}+\sum_{i=0}^{k} w_{i}^{(2)} \varphi\left(w_{i, 0}^{(1)}+w_{i, 1}^{(1)} u(k-\tau)+\sum_{j=1}^{k} w_{i, i+1}^{(1)} v_{j}(k-1)\right)
$$

The neural network training includes in changing the values of its weights in such a way that the error of approximation is acceptable. In the case of recognition of processes of dynamic, sequences of data the recorded of input and output signals are necessary for error of training. Model with approximation accuracy is usually clarified by thesquared errors sum. For some vector of weights w, one has

$$
\left.E(N)=\sum_{N=1}^{p} y(N)-y(N)\right)^{2}
$$

The the Elman neural network model ouputs are acquired from the layer of output units. The difference between actual values and target values is considered as error of system error. The values of error that obtained are spread back to link weights. This operation is put in for using the following equations:

Firstly, from output layer to last hidden layer

$$
\begin{aligned}
& \delta_{N}=f^{\prime}\left(N E T_{N}\right)\left(T_{\left.A R G E T_{N}-O U T_{N}\right)}\right. \\
& \delta_{N}=O U T_{N}\left(1-O U T_{N}\right)\left(T A R G E T_{N}-O U T_{N}\right) \\
& \Delta W_{N j}(n+1)=\gamma \delta_{N} O U T_{N}+\alpha\left[\Delta W_{N j}(n)\right] \\
& W_{N j}^{N E W}=W_{N j}^{O L D}+\Delta W_{N j}(n+1)
\end{aligned}
$$


where TARGET $T_{N}$ presents required output value. $\gamma$ is the value learning rate, $\alpha$ is the value of momentum coefficient, $f^{\prime}\left(N E T_{N}\right)$ represents the value of activation function, $\mathrm{n}$ is the value of iteration number and $\Delta \mathrm{W}$ is the value of change of related weight. This term is attached to the pld weight of corresponding matching to get the new weight. Here, $\delta_{N}$ the value of error gradient at neuron $\mathrm{N}$.

Secondly, from hidden layer to input layer

$$
\begin{aligned}
& \delta_{j}=f^{\prime}\left(N E T_{j}\right) \sum \delta_{N} W_{N j} \\
& \delta_{j}=O U T_{j}\left(1-O U T_{j}\right) \sum \delta_{k} W_{N j} \\
& \Delta W_{j i}(n+1)=\gamma \delta_{j} O U T_{j}+\alpha\left[\Delta W_{j i}(n)\right] \\
& W_{j i}^{N E W}=W_{j i}^{O L D}+\Delta W_{j i}(n+1)
\end{aligned}
$$

The value of bias affects the activation function to force the learning process; therefore, the learning process speed increases. Biases are recalculated as follows. For the of output layer biases, where the letters and symbols have similar meanings

$$
\begin{aligned}
& \Delta W_{B N}(n+1)=\gamma \delta_{N}+\alpha\left[\Delta W_{B N}(n)\right] \\
& W_{B j}^{N E W}=W_{B j}^{O L D}+\Delta W_{B j}(n+1)
\end{aligned}
$$

and for the biases of hidden layer

$$
\begin{aligned}
& \Delta W_{B j}(n=1)=\gamma \delta_{j}+\alpha\left[\Delta W_{B j}(n)\right] \\
& W_{B j}^{N E W}=W_{B j}^{O L D}+\Delta W_{B j}(n+1)
\end{aligned}
$$

\section{RESULTS AND ANALYSIS}

The data collected for two years (2014-2015) of National Control Center (NCC) in Iraq that represented power demand for every hour. We proposed prediction by using Elman neural network to evaluate power demand that showing in figures below. The $\mathrm{x}$ axes represent hours for one day, but $\mathrm{y}$ axes represent power demand in maga Watt (Mw).the blue colure represent National Control Center prediction for power demand (MRN) and red colure represent our prediction proposed. From Figure 2 its clear closed the shapes to each other that represent the governorates demand in January 22nd 2014. And also figures from Figure 3 until Figure 5 show Governorates demand load for random days in 2014 year. The peak power demand was record in 19h (7pm) that $14800 \mathrm{MW}$ (for 22nd 2014 day) at night. From all figure absorb the peak power demand registered at 7 pm. From Figure 6 to Figure 9 appear random samples days for 2015 year. The peak power demand record at $6 \mathrm{pm}$ was $16500 \mathrm{Mw}$ as shown in figure 6 for 16th 2015 day.

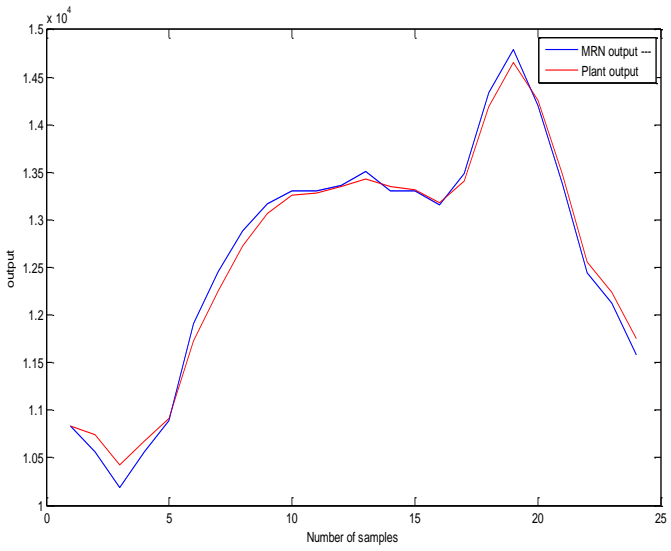

Figure 2. Governorates demand load in January 22nd 2014

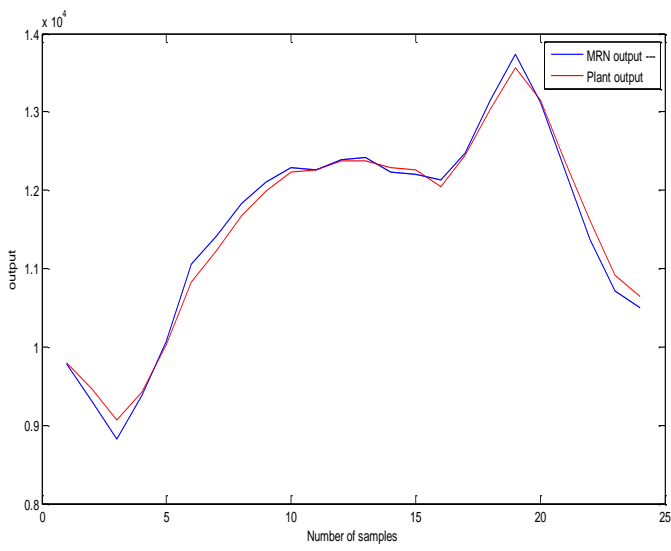

Figure 3. Governorates demand load in February 26th 2014 


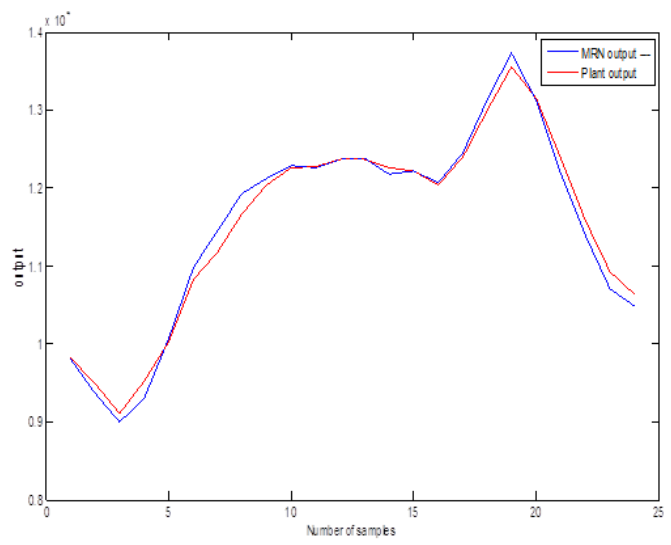

Figure 4. Governorates demand load in March 3rd 2014

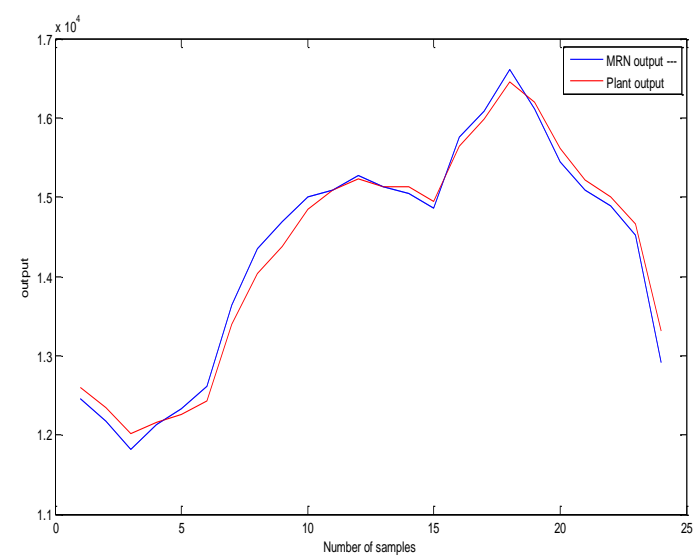

Figure 6. Governorates demand load in January 16th 2015

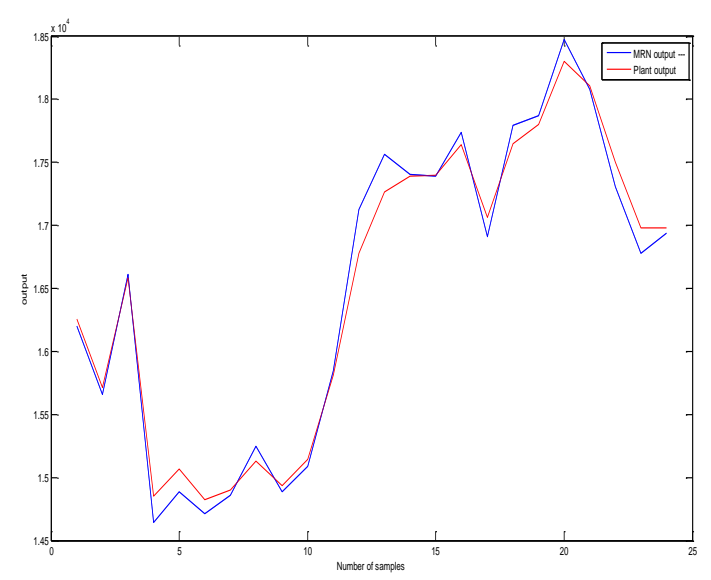

Figure 8. Governorates demand load in July 7th 2015

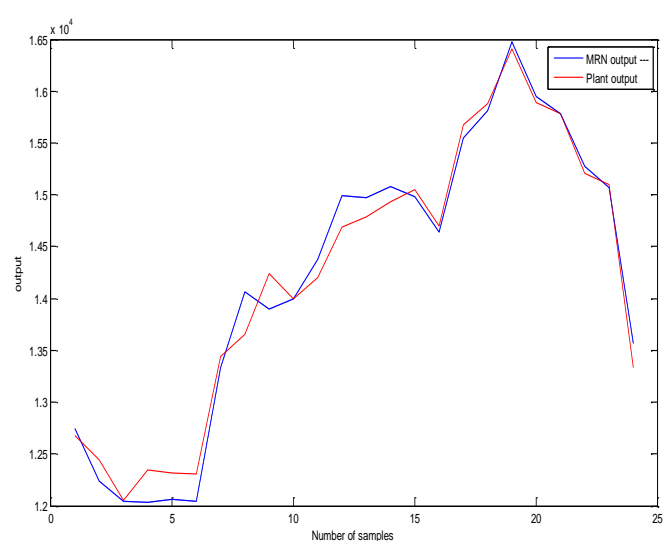

Figure 5. Governorates demand load in September 20th 2014

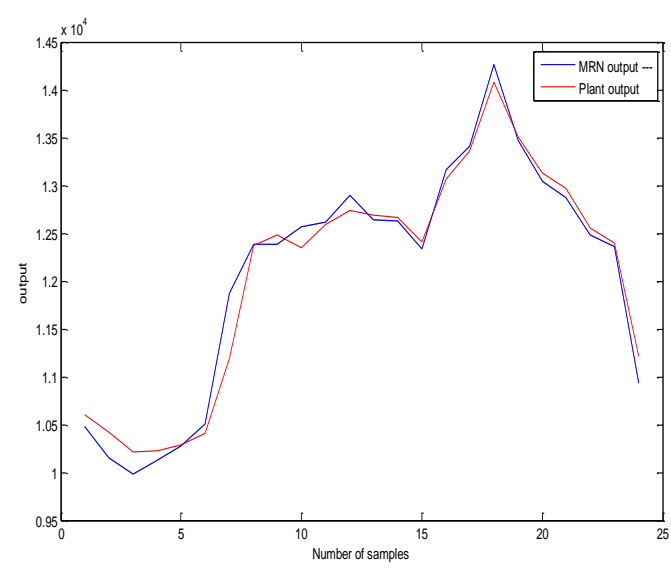

Figure 7. Governorates demand load in March 3rd 2015

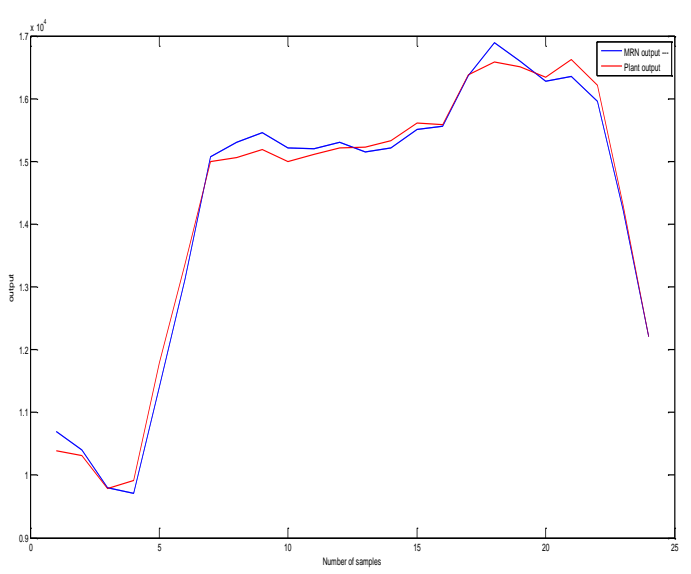

Figure 9. Governorates demand load in December 12nd 2015

To test the model that proposed can check without input data recorded, therefore the Figure 10 shown behavior the load as estimation of Governorates demand load in January 12nd 2016. And also the random other day was shown in Figure 11 estimation of Governorates demand load in June 1st 2016. 


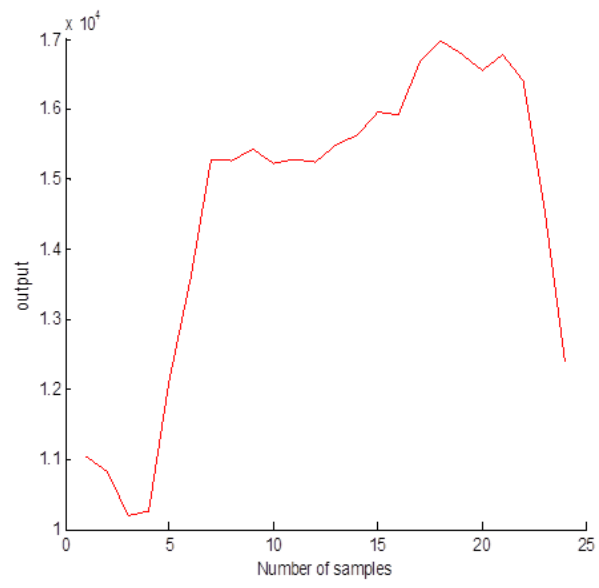

Figure 10. Estimation of Governorates demand load in January 12 nd 2016

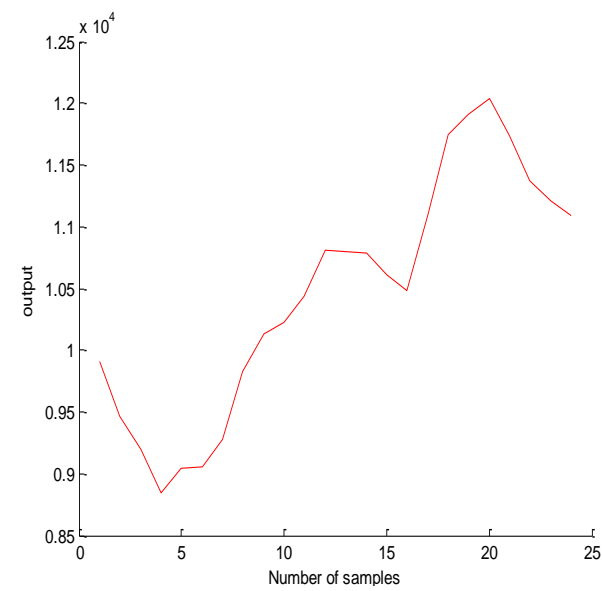

Figure 11. Estimation of Governorates demand load in June 1 st 2016

Table 1. Shows the error beween the true value and estimation values by neural network

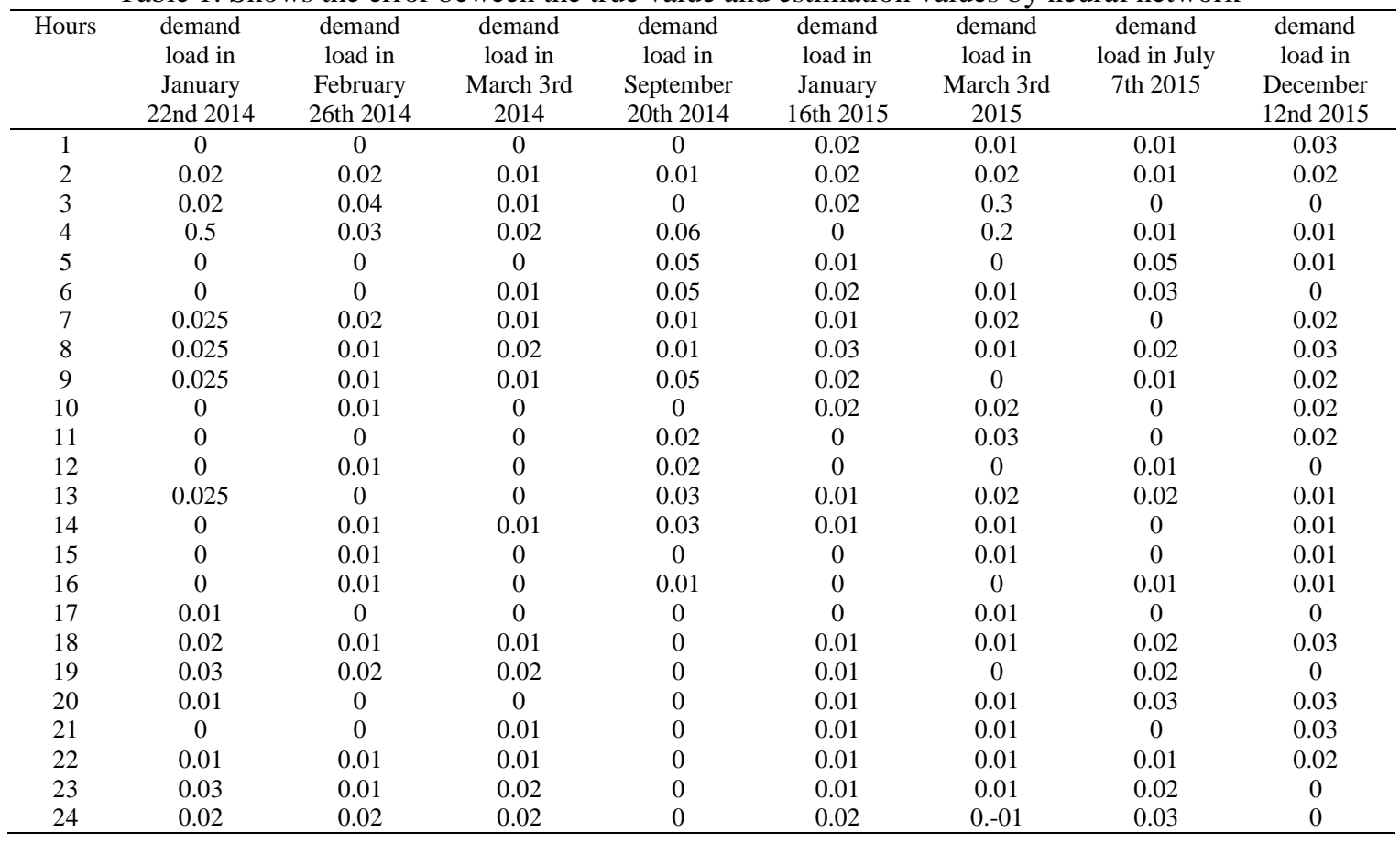

\section{CONCLUSION}

The power demand prediction still is controversial between the researchers due to exist many factors non constant. The power demand illustrated little at $1 \mathrm{Am}$ to $5 \mathrm{Am}$ morning then increase the power consumption then approximation stable until $7 \mathrm{pm}$, at $7 \mathrm{pm}$ is the peak power demand as illustrated in winter. In this paper the modeling designed was effective to pridect the power demand for Iraq utility network. From Table 1 shows the error between the true valu and estimation value by neural network is very low ant that means the data of true and estimation value is very close and that refres that the Elman neural Netwrok is good method to estimation data and by validation can proof the estimation of future data for any power demand as shown in Figure 10 and Figure 11.

\section{ACKNOWLEDGEMENTS}

We want thank National Control Center (NCC) in Iraq for all the helping and the cooperation by support as at all data for 2 years for every hour power demand and power consumption for Iraq. 


\section{REFERENCES}

[1] S. Fan and L. Chen, "Short-term load forecasting based on an adaptive hybrid method," IEEE Transactions on Power Systems, vol. 21, pp. 392-401, 2006.

[2] J. Nagi, et al., "A computational intelligence scheme for the prediction of the daily peak load," Applied Soft Computing, vol. 11, pp. 4773-4788, 2011.

[3] A. I. Ismael, "Off-Grid Electricity Generation with Hybrid Renewable Energy Technologies in Iraq: An Application of Homer."

[4] M. T. Hagan, et al., "Neural network design, PWS Pub," Co., Boston, vol. 3632, 1996.

[5] S. Haykin, "Neural networks: a comprehensive foundation Prentice-Hall Upper Saddle River," NJ MATH Google Scholar, 1999.

[6] S. Osowski, "Neural Networks for Information Processing," Presented at the Oficyna Wydawnicza Politechniki Warszawskiej, Warszawa, in Polish, 2006.

[7] J. L. Elman, "Finding structure in time," Cognitive science, vol. 14, pp. 179-211, 1990.

[8] J. A. Chambers, "Recurrent neural networks for prediction: learning algorithms, architectures and stability," Wiley, 2001.

[9] K. A. S. Majbor, et al., "The Iraqi Grid Electrical Demand: Questionable Forecast," Al ma'moon college. J. Electrical and Electronic Engineering, 2017.

[10] A. M. Dakhil, "Short Term Load Forecasting Based Artificial Neural Network," Iraq J. Electrical and Electronic Engineering, vol/issue: 10(1), 2014.

\section{BIOGRAPHIES OF AUTHORS}

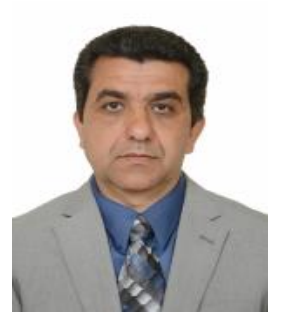

Lafta E. Jumaa Alkurawy received the B.S., and M.S. degree in Control and systems from Technology University, Baghdad, Iraq, in 1996 and 2003 respectively. He received the Ph.D. degree in Electrical and Computer Engineering from University of Missouri in Columbia, USA, in 2013.Since 2003, I have been with University of Diyala, College of engineering, Diyala, Iraq as a lecturer. His current research interests include modeling, control, Numerical analysis and nonlinear

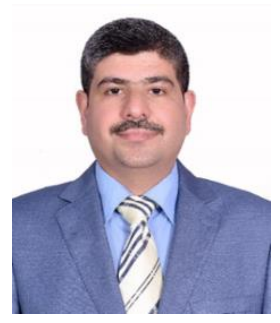

Ammar Issa received his B.Sc from University of Baghdad in Iraq in 2001, MSc from University Tenaga nosional (uniten) in Malaysia at 2013, work at college of engineering University of Diyala, Ira as assistant lecture. His current research interests include power electronic, electrical car, renable energy. 